\title{
In vivo Image of Cerebral Amyloid Angiopathy in an Alzheimer's Disease Mouse Model
}

\author{
Jinho Kim, Yong Jeong \\ Department of Bio and Brain Engineering, KAIST, Daejeon, Korea
}

\section{Dear Sir:}

We would like to share an in vivo image of cerebral amyloid angiopathy (CAA) in an Alzheimer's disease (AD) mouse model. In $\mathrm{AD}$, insoluble amyloid beta $(\mathrm{A} \beta)$ protein forms plaques in the parenchyma and also accumulates along the vessel walls. ${ }^{1}$ The $A \beta$ usually accumulates in the tunica intima and tunica media layers of the vessels. $\mathrm{CAA}$ in $\mathrm{AD}$ is attributed to the failure of $A \beta$ clearance from the brain through perivascular drainage pathways. ${ }^{2}$ In addition, CAA is thought to be responsible for the small vessel pathology that leads to ischemic changes in the white matter in $\mathrm{AD}$. Thus, observation of CAA in regards to white matter lesions or other pathophysiology is important in understanding the development of $\mathrm{AD}$. However, neuropathological studies have typically relied on sections from brain tissues at autopsy, which hampers understanding of the dynamics and topographic distribution of CAA. Cutting-edge optical techniques such as multi-photon laser scanning microscopy enable us to observe CAA in live animals in $3 \mathrm{D}^{3}$

In this study, we used 7-month-old male APPswe/PS1 $1 \mathrm{E} 9$ transgenic mice (Jackson Laboratory). One day prior to imaging, methoxy-X04 (5 mg/kg; dissolved in 10\% DMSO, 45\% propylene glycol, and $45 \%$ phosphate-buffered saline) was injected intraperitoneally. This probe has been used for in vivo imaging of amyloid plaques in several studies. ${ }^{4,5}$ On the day of surgery, the mouse was anesthetized with ketamine and xylazine $(0.12 \mathrm{mg} / \mathrm{g}$ and $0.01 \mathrm{mg} / \mathrm{g}$, respectively), and a $2 \times 2 \mathrm{~mm}$ craniotomy was made over the somatosensory area leaving the dura intact. The cortex was covered with $1 \%$ agarose and a glass cover slip. Texas Red-dextran ( $70 \mathrm{kDa}, 100 \mu \mathrm{L}, 5 \mathrm{mg} / \mathrm{mL})$ was injected via the tail vein. All procedures were approved by the
KAIST Institutional Animal Care and Use Committee (IACUC). We used a multi-photon laser scanning microscope (LSM510, Zeiss, Germany) and a tunable near-infrared femtosecond pulsed-laser (Chameleon II, Coherent, USA). Images

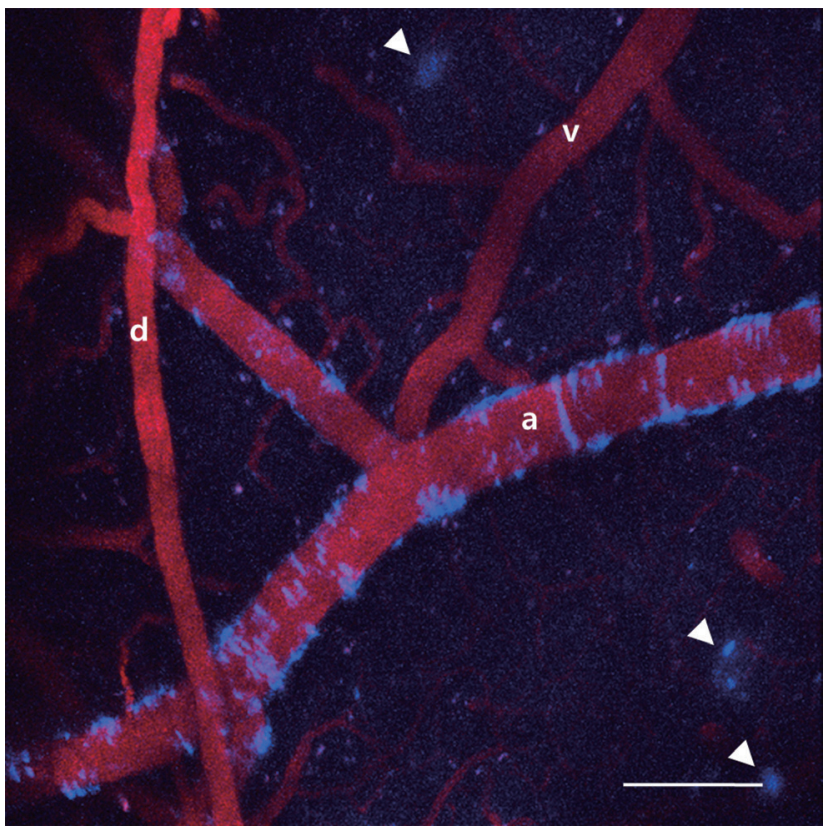

Figure 1. Plaque and cerebral vessel imaging in an APPswe/PS1 $\triangle E 9$ transgenic mouse (7-month-old; male). Methoxy-X04 (5 mg/kg) was injected intraperitoneally 1 day before the imaging session for plaque imaging. Texas Reddextran $(70 \mathrm{kDa})$ was injected intravenously on the day of imaging for vessel imaging. Imaging using two-photon laser scanning microscopy was performed up to a depth of $100 \mu \mathrm{m}$ from the exposed dura. Amyloid aggregates (blue) are deposited on the cerebral arteriole wall (cerebral amyloid angiopathy; CAA) as well as in the brain parenchyma (amyloid plaques). CAA is not observed around the veins or dura vessels. (Red, cerebral blood vessel stained with Texas Red-dextran; a, arteriole; d, dura vessel; v, vein; arrowheads, amyloid plaques; scale bar $=100 \mu \mathrm{m}$ )

This is an Open Access article distributed under the terms of the Creative Commons Attribution Non-Commercial License (http://creativecommons.org/licenses/by-nc/3.0/) which permits unrestricted non-commercial use, distribution, and reproduction in any medium, provided the original work is properly cited. 
were taken using a $20 \times$ objective lens (NA 1.0; Carl Zeiss) with a frame rate of $0.5-1 \mathrm{~Hz}$. All images were obtained using the pulsed laser at an excitation wavelength of $800 \mathrm{~nm}$. We discriminated between arterioles and venules based on the direction of red blood cell flow and the morphology of the vessels.

As shown in the Figure 1 (and supplementary movie clip 1 for $z$-stack image), $A \beta$ deposits were wrapped around the vessel wall in patches. Most plaques did not form complete rings forms at this stage. Seven months is still relatively young, and older mice would have dense $A \beta$ deposits and complete ring forms of CAA. Interestingly, CAA was not observed in either the veins or the dura vessels. ${ }^{1}$ This finding supports the concept that $\mathrm{CAA}$ is formed by failure of $\mathrm{A} \beta$ elimination along the periarterial wall, but not along the peri-venous wall. ${ }^{6}$

\section{References}

1. Biffi A, Greenberg SM. Cerebral amyloid angiopathy: a systematic review. J Clin Neurol 2011;7:1-9.

2. Weller RO, Preston SD, Subash M, Carare RO. Cerebral amyloid angiopathy in the aetiology and immunotherapy of Alzheimer disease. Alzheimers Res Ther 2009;1:6.

3. Dorr A, Sahota B, Chinta LV, Brown ME, Lai AY, Ma K, et al. Amyloid- $\beta$-dependent compromise of microvascular structure and function in a model of Alzheimer's disease. Brain 2012; 135:3039-3050.
4. Klunk WE, Bacskai BJ, Mathis CA, Kajdasz ST, McLellan ME, Frosch MP, et al. Imaging Abeta plaques in living transgenic mice with multiphoton microscopy and methoxy-X04, a systemically administered Congo-red derivative. J Neuropathol Exp Neurol 2002;61:797-805.

5. Kim J, Jeong Y. Augmentation of sensory-evoked hemodynamic response in an early Alzheimer's disease mouse model. $J$ Alzheimers Dis 2013;37:857-868.

6. Weller RO, Subash M, Preston SD, Mazanti I, Carare RO. Perivascular drainage of amyloid-beta peptides from the brain and its failure in cerebral amyloid angiopathy and Alzheimer's disease. Brain Pathol 2008;18:253-266.

Correspondence: Yong Jeong Department of Bio and Brain Engineering, KAIST, 291 Daehak-ro, Yuseong-gu, Daejeon 305-701, Korea

Tel +82-42-350-4324, Fax +82-42-350-4310

Email:yong@kaist.ac.kr

Received: December 11, 2014

Revised: January 9, 2015

Accepted: January 12, 2015

This research was supported by the R\&D Program of Daegu-Gyeongbuk Medical Innovation.

The authors have no financial conflicts of interest. 